\title{
Lung function in adult idiopathic scoliosis: a 20 year follow up
}

\author{
Kerstin Pehrsson, Björn Bake, Sven Larsson, Alf Nachemson
}

\begin{abstract}
Severe idiopathic scoliosis may lead to respiratory failure, which can be treated by assisted ventilation. Twenty four patients with surgically untreated idiopathic scoliosis who had been examined in 1968 were re-examined in 1988 to assess changes in lung function and risk factors for respiratory failure. The patients were aged 15-67 years in 1968 and had a scoliotic angle of $10-190^{\circ}$ and a vital capacity of $1 \cdot 0-6 \cdot 0$ litres. Spirometric values and scoliotic angles were determined in 1968 and 1988, and arterial blood gas tensions in 1988. The decline in spirometric values over the 20 years was of the same magnitude as the predicted decline due to aging. Arterial blood gas tensions in 1988 were strongly correlated with the scoliotic angles and spirometric indices recorded in 1968. Hypoxaemia and hypercapnia was seen in four patients in 1988 (then aged 43-67 years) and these were the four patients who had a vital capacity below $43 \%$ predicted in 1968. The remaining 20 patients had blood gas values within normal limits. Two further patients had died from respiratory failure before 1988, so a total of six patients had developed respiratory failure. In a multiple logistic analysis vital capacity expressed as \% predicted in 1968 was the strongest predictor of the development of respiratory failure, followed by the scoliotic angle. Respiratory failure occurred only in patients who had a vital capacity below $45 \%$ predicted in 1968 and an angle greater than $110^{\circ}$. Thus respiratory failure develops in adults with scoliosis with a large angle and a low vital capacity when normal aging reduces the ventilatory capacity further. Such individuals merit close follow up.
\end{abstract}

Medicine

K Pehrsson

$S$ Larsson

Department of Clinical Physiology B Bake

Department of Orthopaedics A Nachemson

University of Göteborg, Renström's and Sahlgren's Hospitals, Göteborg, Sweden

Reprint requests to: Dr K Pehrsson, Renström's Hospital, Box 17301, S-40264 Göteborg, Sweden. Accepted 26 April 1991

Patients with untreated scoliosis run an increased risk of developing respiratory failure $^{12}$ and of premature death. ${ }^{34}$ Surgical treatment with Harrington instrumentation and fusion has been used in Sweden since 1965. In these patients the risk of severe impairment of lung function ${ }^{5}$ is low. There are still patients older than 40 years, however, who have not undergone surgery and who run an increased risk of developing respiratory failure. We decided to study the long term changes in lung function and its relation to respiratory failure in patients with untreated idiopathic scoliosis.

In 1968 a group of patients with scoliosis was studied in Göteborg and scoliotic angles, lung function, and respiratory symptoms were assessed. ${ }^{67}$ We have now re-examined those with unfused idiopathic scoliosis and analysed the data on change in lung function, presence of respiratory failure, and death. The purpose was to investigate the decline in lung function and to identify risk factors for the development of respiratory failure.

\section{Methods}

PATIENTS

The patients in the present study were taken from a group of 45 patients with scoliosis studied in 1968 by Bjure et $a^{6}$ and Bake et al. ${ }^{7}$

Between 1968 and 1988 eight patients died, all with unfused idiopathic scoliosis. Two patients could not be traced, one patient did not wish to take part in the present investigation, and seven patients born in the 1940 s or 1950s had undergone spinal fusion. Three were excluded because they had paralytic scoliosis. Hence 24 patients with unfused idiopathic scoliosis remained for follow up in 1988.

The age of the 24 patients ranged from 15 to 67 years in 1968, the scoliotic angles from $10^{\circ}$ to $190^{\circ}$ and the vital capacity from 1.0 to 6.0 litres.

The scoliotic curves were classified as thoracic if the apical vertebra was between the third and 10th thoracic vertebrae and as thoracolumbar if the apex of the curve was between the 11th thoracic and the second lumbar vertebrae. No pure lumbar curves were seen but one patient had a double primary curve.

\section{STUDY PROTOCOL}

In both 1988 and 1968 we elicited (1) scoliotic angles; (2) respiratory symptoms and smoking habits according to a questionnaire;
(3) quasi-static vital capacity (VC), functiona residual capacity (FRC), residual volume (RV), total lung capacity (TLC), and forced expiratory volume in one second $\left(\mathrm{FEV}_{1}\right)$.

In 1988 we obtained in addition (1) diagnoses according to death certificates; (2) available case records; (3) VC in supine position, maximal inspiratory pressure (MIP), maximal expiratory pressure (MEP), and arterial blood gas tensions. 
Table 1 Lung function results obtained in 1968 and in 1988 in 24 patients with unfused idiopathic scoliosis

\begin{tabular}{|c|c|c|c|c|c|c|}
\hline & \multicolumn{3}{|l|}{1968} & \multicolumn{3}{|l|}{1988} \\
\hline & Mean & $S D$ & $n$ & Mean & $S D$ & $n$ \\
\hline $\mathrm{VC}(1)$ & $2 \cdot 5$ & $1 \cdot 2$ & 20 & $2 \cdot 1$ & $1 \cdot 2$ & 20 \\
\hline VC ( $\%$ pred) & 65 & 24 & 20 & 64 & 27 & 20 \\
\hline $\mathrm{FEV}_{1}(\mathrm{l})$ & $2 \cdot 0$ & 0.9 & 20 & $1 \cdot 6$ & $1 \cdot 0$ & 20 \\
\hline FRC (1) & $2 \cdot 0$ & 0.9 & 16 & $2 \cdot 2$ & $0 \cdot 8$ & 16 \\
\hline RV (1) & $1 \cdot 3$ & 0.5 & 16 & $1 \cdot 6$ & 0.5 & 16 \\
\hline TLC (1) & $3 \cdot 7$ & $1 \cdot 7$ & 16 & 3.9 & 1.5 & 16 \\
\hline VC supine (1) & & & & $2 \cdot 0$ & 1.5 & 20 \\
\hline MIP (\% pred) & & & & 47 & 28 & 20 \\
\hline MEP ( $\%$ pred) & & & & 51 & 29 & 20 \\
\hline $\mathrm{PaO}_{2}(\mathrm{kPa})$ & & & & $10 \cdot 4$ & 1.9 & 24 \\
\hline $\mathrm{PaCO}_{2}(\mathrm{kPa})$ & & & & 5.5 & $1 \cdot 0$ & 24 \\
\hline Standard bicarbonate $(\mathrm{mmol} / \mathrm{l})$ & & & & $25 \cdot 4$ & $3 \cdot 0$ & 24 \\
\hline
\end{tabular}

VC-vital capacity; $\mathrm{FEV}_{1}$-forced expiratory volume in one second; FRC-functional residual capacity; RV-residual volume; TLC - total lung capacity; MIP-maximum inspiratory pressure; $\mathrm{MEP}-$ maximum expiratory pressure; $\mathrm{PaO}_{2}$-arterial oxygen tension; $\mathrm{PaCO}_{2}-$ arterial carbon dioxide tension.

\section{DETERMINATION OF THE DEGREE OF SCOLIOSIS (COBB)}

The scoliotic angle was determined by the same orthopaedic surgeon in 1988 as in 1968. Determination of the apical vertebra and angle was made according to the method of $\mathrm{Cobb}^{8}$ from radiographs taken in the standing position.

\section{Percent of predicted normal}

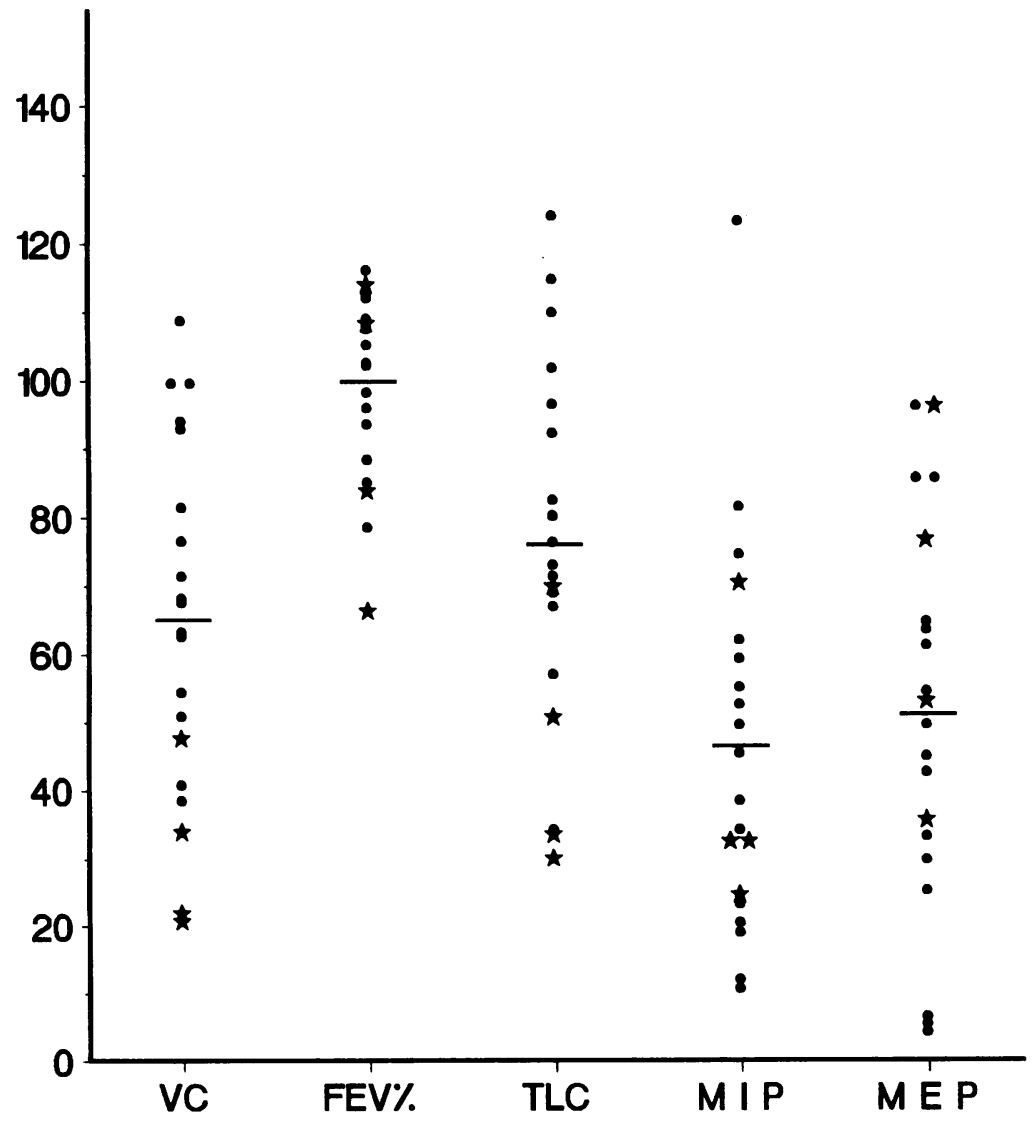

Figure 1 Individual results of some lung function tests from 1988 expressed as \% predicted. The horizontal lines give mean values. The four patients with respiratory failure (*), are in the low range, especially with regard to vital capacity (VC) and total lung capacity (TLC). FEV\%-forced expiratory volume in one second as percentage of $V C ; M I P$-maximum inspiratory pressure; $M E P$-maximum expiratory pressure.
QUESTIONNAIRE

The same translation of a British questionnaire ${ }^{9}$ of respiratory symptoms was used in 1968 and in 1988. It contains questions about cough, phlegm, wheezing, dyspnoea, and smoking habits. Dyspnoea severity was graded from 1 to 5 . Grade 3 means breathlessness when the subject is walking with someone else on level ground.

\section{LUNG FUNCTION INVESTIGATION}

Static lung volumes were determined by the helium dilution technique. $\mathrm{FEV}_{1}$ and $\mathrm{VC}$ were measured with a water spirometer (Bernstein) in the sitting position on both occasions and in the supine position in 1988 . The same laboratory technician performed the investigations in 1968 and 1988. Normal values were predicted according to formulae from Berglund $e t a l^{10}$ and were corrected for $\mathrm{VC}$ for loss of height due to scoliosis according to the formula of Lindh and Bjure. ${ }^{5}$

Maximal inspiratory pressure and maximal expiratory pressure were obtained at FRC. ${ }^{11} 12$ Normal values were predicted from Decramer et $a l^{11}$ and Lurie et al. ${ }^{12}$

Arterial blood gas measurements, including oxygen tension $\left(\mathrm{PaO}_{2}\right)$, carbon dioxide tension $\left(\mathrm{PaCO}_{2}\right)$, and standard bicarbonate, were determined (Radiometer ABL2) in samples of blood obtained from the patient when semirecumbent after 10 minutes' rest. Respiratory failure was defined as $\mathrm{PaO}_{2}$ below $8 \mathrm{kPa}$ or $\mathrm{PaCO}_{2}$ above $6.5 \mathrm{kPa}$, or both.

\section{STATISTICS}

Fisher's non-parametric permutation test ${ }^{13}$ was used for comparison between groups. A multivariate analysis of predictors for respiratory failure was carried out with a stepwise logistic model. ${ }^{14}$

\section{Results}

The eight patients studied in 1968 (five women and three men) who had died during the follow up period had a mean age at death of 67 years. Respiratory failure due to scoliosis was the cause of death in two patients (aged 54 and 75 years) according to their death certificates and case records. They are included in the analysis of risk for development of respiratory failure (see below). The mean age of the 24 patients at follow up in 1988 was 62 years. There were 20 women and four men. Twenty of the 24 patients were able to complete the study protocol and four patients cooperated only with the blood gas determination.

\section{MEASUREMENTS PERFORMED IN 1988 (TABLE 1,} FIG 1).

Mean VC was $2 \cdot 1$ litres ( $64 \%$ predicted) and mean TLC 3.91 (75\% predicted).

Respiratory failure was present in four of the 24 patients. Their blood gas values showed a combination of a low $\mathrm{PaO}_{2}(5 \cdot 9-7 \cdot 7 \mathrm{kPa})$ and an increased $\mathrm{PaCO}_{2}(6 \cdot 4-8 \cdot 6 \mathrm{kPa})$.

Mean supine VC was 2.01 in the 20 patients who were able to cooperate. In three patients 
Table 2 Numbers of patients who had respiratory symptoms and who smoked, according to a questionnaire answered by 14 patients with idiopathic and unfused scoliosis in 1968 and 1988

\begin{tabular}{lll}
\hline & 1968 & 1988 \\
\hline Cough & 4 & 6 \\
Phlegm & 2 & 3 \\
Wheezing & 9 & 8 \\
Dyspnoea & 5 & 8 \\
Current smokers & 8 & 2 \\
\hline
\end{tabular}

VC fell by more than $15 \%$ on lying supine (VC sitting - VC supine) $\times 100 /$ VC sitting).

MIP and MEP showed a wide variation (fig 1). Mean MIP was $47 \%$ of predicted (range 11-124\%), and mean MEP $51 \%$ of predicted (range 5-97\%). There was no significant correlation between arterial blood gas tensions in 1988 and MIP or MEP.

COMPARISON BETWEEN RESULTS IN 1968 AND IN 1988

The scoliotic angle increased in four patients (from $30^{\circ}$ to $40^{\circ}, 40^{\circ}$ to $70^{\circ}, 40^{\circ}$ to $55^{\circ}$, and $100^{\circ}$ to $125^{\circ}$ ) and was unchanged in the rest of the group. This resulted in a mean (SD) increase from $79^{\circ}\left(49^{\circ}\right)$ to $86^{\circ}\left(46^{\circ}\right)$.

The respiratory symptoms and smoking habits, reported in the questionnaires in 1968 and 1988 by 14 patients (it was possible to trace only 14 questionnaires from 1968), are summarised in table 2. Wheezing and dyspnoea were common symptoms on both occasions; the number of smokers had decreased considerably by 1988 .

The mean decline in both $\mathrm{VC}$ and $\mathrm{FEV}_{1}$ was 0.41 (table 1 ).

PROGNOSTIC IMPORTANCE OF RESULTS OBTAINED IN 1968

Arterial blood gas tensions obtained in 1988 are plotted in figure 2 against the scoliotic angles and VC \% predicted determined in 1968. Both scoliotic angles and spirometric results showed strong non-linear correlations with blood gas tensions $(p<0.001)$. There is a threshold value for the development of respiratory failure at a VC recorded in 1968 of around $43 \%$. The four patients with a VC below $43 \%$ predicted
Figure 2 Vital capacity (VC, \% predicted) and scoliotic angles in 1968 plotted against arterial blood gas tensions in 1988. The closed circles indicate the four patients with respiratory failure. The correlation coefficients between VC \% predicted in 1968 and blood gas values (arterial oxygen and carbon dioxide tensions) ( $\mathrm{PaO}_{2}, \mathrm{PaCO}_{2}$ ) and standard bicarbonate $(S B C)$ ) in 1988 in an inverse model $(y=a+b / x)$ were $-0 \cdot 74,0 \cdot 86$, and $0 \cdot 72$.
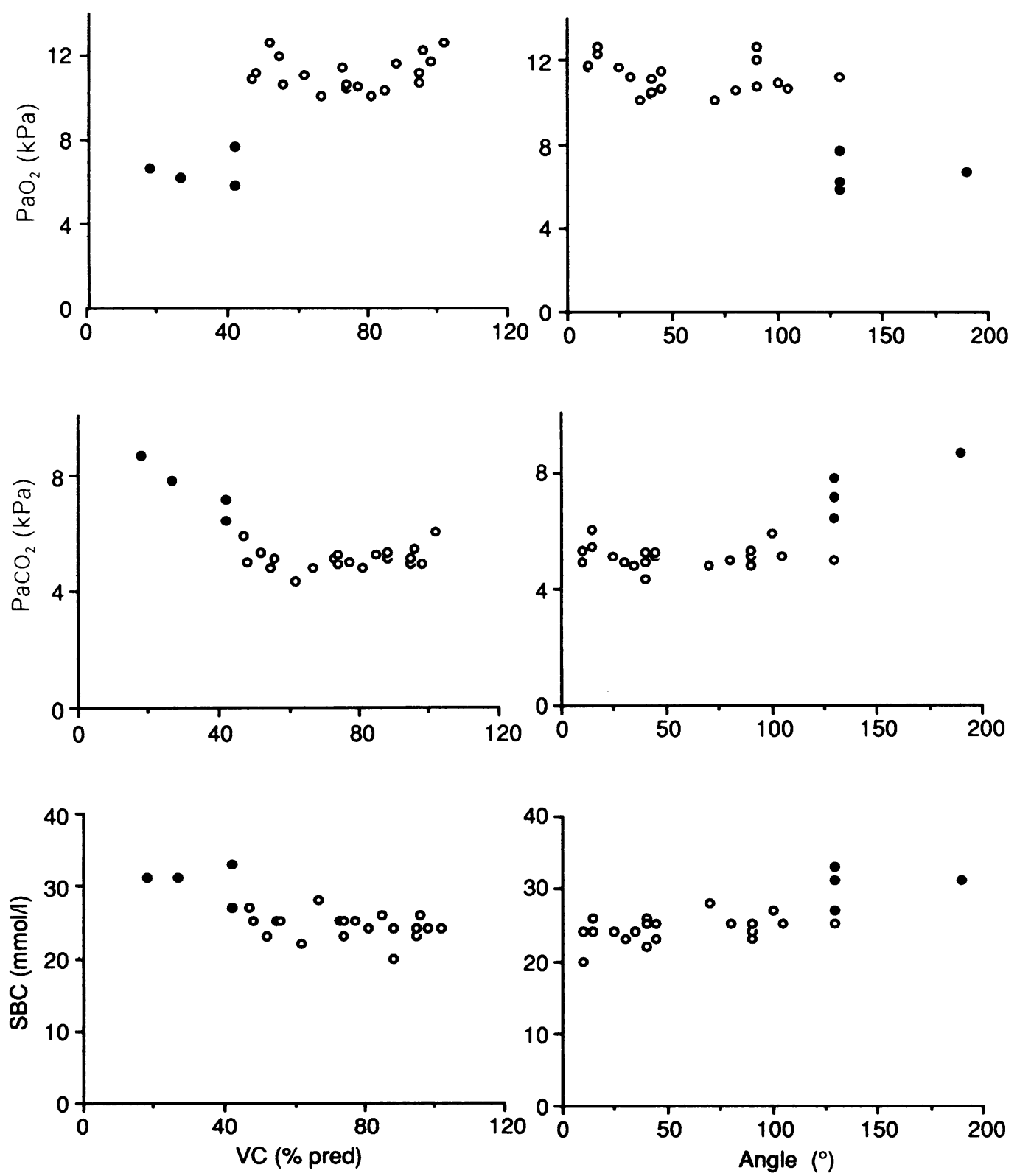
Table 3 Comparison between various variables determined in 1968 in patients with and without respiratory failure in 1988

\begin{tabular}{|c|c|c|c|c|c|}
\hline & \multicolumn{2}{|c|}{ Respiratory failure ( $n=6$ ) } & \multicolumn{3}{|c|}{ No respiratory failure $(n=20)$} \\
\hline & Mean & $S E M$ & Mean & $S E M$ & $p \S$ \\
\hline Angle $\left({ }^{\circ}\right)$ & 137 & 11 & 55 & 8 & $<0.001$ \\
\hline $\mathrm{VC}(1)$ & $1 \cdot 3$ & $0 \cdot 1$ & $2 \cdot 8$ & 0.2 & $<0.01$ \\
\hline VC $(\%$ pred $)$ & 34 & 4 & 76 & 4 & $<0.001$ \\
\hline VC $\left(\%\right.$ pred, no correction $\left.{ }^{\star}\right)$ & 41 & 5 & 79 & 4 & $<0.001$ \\
\hline FEV $_{\text {(1) }}$ & $1 \cdot 1$ & $0 \cdot 2$ & $2 \cdot 3$ & 0.2 & $<0.01$ \\
\hline $\operatorname{TLC}(1)+$ & $2 \cdot 3$ & $0 \cdot 2$ & $4 \cdot 1$ & $0 \cdot 4$ & $<0.01$ \\
\hline Dyspnoea + & $3 \cdot 2$ & $0 \cdot 7$ & $1 \cdot 7$ & $0 \cdot 3$ & $<0.05$ \\
\hline Wheezing + & $1 \cdot 0$ & 0 & 0.4 & $0 \cdot 1$ & $<0.05$ \\
\hline
\end{tabular}

*For loss of height due to scoliosis.

tn $=4$ and 17 .

tn $=6$ and 15. Dyspnoea was ranked from 1 to 5 , with increasing severity. Absence of wheezing was graded as 0 and wheezing as 1 . \$For FRC, RV, and smoking habit differences were non-significant.

Abbreviations as in table 1 .

in 1968 had hypoxaemia and hypercapnia in 1988. The remaining 20 patients had normal $\mathrm{PaO}_{2}$ and $\mathrm{PaCO}_{2}$ values.

Six of the patients (two dead and four living) with unfused idiopathic scoliosis developed respiratory failure during the follow up period; 20 patients remained without respiratory failure. The results of the analysis designed to predict the development of respiratory failure are as follows.

A univariate analysis between respiratory failure and the different variables obtained in 1968 was carried out initially and showed that large angle, low spirometric values and low TLC were strong predictors of the development of respiratory failure (table 3 ). When respiratory symptoms and smoking habits in 1968 were related to respiratory failure there was a statistical correlation for dyspnoea and wheezing but not for smoking habits.

The relative order of importance of the different risk factors was then described on the basis of a multivariate stepwise logistic analysis. VC \% predicted in 1968 was the strongest predictor and was the only variable selected by this procedure. This variable correctly predicted the presence or absence of respiratory failure in 1988 in all patients. The scoliotic angle in 1968 classified 25 of 26 patients correctly. The spirometric results and the angle were highly correlated; hence they excluded each other in the multivariate analysis.

\section{Discussion}

The lung function results recorded in 1988 in this study are in line with results reported by other investigators ${ }^{15}$ in cross sectional studies of patients with idiopathic scoliosis. The scoliosis was classified as idiopathic on the basis of a detailed clinical examination. We found restrictive ventilatory impairment with low mean VC and TLC (table 1, fig 1). These measurements were strongly and inversely related to the scoliotic angle. There was a wide range of MIP and MEP in our patients (table 1, fig 1), as in the normal population. ${ }^{11}{ }^{12}$ The mean values were reduced, however, to $47 \%$ and $51 \%$ predicted, indicating low respiratory muscle efficiency in our patients. This is also in line with results of other studies. ${ }^{16}$ The mechanical efficiency of the respiratory muscles, especially the diaphragm, is probably reduced by the unfavourable position of the diaphragm in a severely distorted chest. ${ }^{16}$ Lisboa et $a l^{17}$ found a significant correlation between MIP and both $\mathrm{PaO}_{2}$ and $\mathrm{PaCO}_{2}$ in patients with severe scoliosis. The present study did not confirm those results, as we found no correlation between blood gases and either MIP or MEP.

The strongest predictors of respiratory failure in 1988 were a large scoliotic angle and low spirometric results in 1968 . The patients in this study had reached skeletal maturity in 1968 without developing respiratory failure. In such patients respiratory failure might develop when there is a further reduction of VC. Theoretically VC might deteriorate in these patients more rapidly than in people without scoliosis because of increasing deformity of the chest or other factors, or it might decline as expected as a result of aging.

In the present study there was no support for the first possibility. None of the patients who developed respiratory failure had progression of the thoracic curves. Increasing curves have been reported by Weinstein and Ponseti, ${ }^{18}$ especially in thoracic curves that had reached $50-80^{\circ}$ at skeletal maturity. Our results show that respiratory failure may develop despite an unchanged scoliotic angle.

An exaggerated decline in VC due to other factors might also in some cases lead to respiratory failure. This was suggested by Branthwaite, $^{2}$ who retrospectively collected lung function values from a group of patients with idiopathic scoliosis. Two patients (fig 3 ) in the present study showed an exaggerated decline of spirometric values despite an unchanged scoliotic angle. In one the decline might be related to the scoliotic process as she had reduced mobility of the right hemidiaphragm and a large diaphragmatic hernia. Poor diaphragmatic function in this patient might be related to the scoliosis. The other patient was an obese smoker.

The expected reduction of VC resulting from increasing age might provoke respiratory failure in patients with severe idiopathic scoliosis. In our study the patients as a group showed only age predicted changes between 1968 and 1988 (table 1) and the same is true for the patients who developed respiratory failure (fig 3). The expected decline due to increasing 
Figure 3 Individual measurements of vital capacity (VC) and forced expiratory volume in one second ( $F E V$ ) in 1968 and in 1988. The four patients with respiratory failure (broken lines) started with the lowest values and declined according to the age prediction.

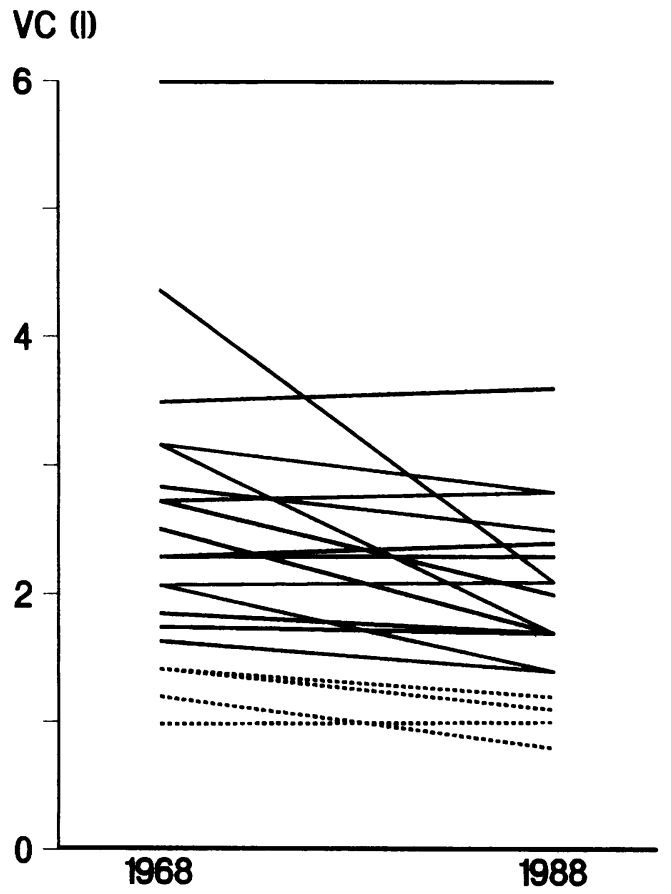

age (calculated for a sex ratio of 17 women and 3 men) is 0.41 for VC and 0.61 for $\mathrm{FEV}_{1}$. In our study the mean decline in both VC and FEV was 0.41 . Our results suggest therefore that in adult patients with idiopathic scoliosis aging is the major cause of decline in VC and therefore of the development of respiratory failure.

Six patients had developed respiratory failure during the follow up, none having had respiratory failure in 1968 according to case records. The apical vertebra was located between 6 and 9 in these patients. The scoliosis was convex to the right in four and to the left in two. Nachemson ${ }^{3}$ and Nilsonne ${ }^{4}$ in two studies in 1968 described an increased mortality due to respiratory failure in patients with idiopathic scoliosis. In contrast, Weinstein ${ }^{19}$ in 1981 in a follow up of around 200 patients with idiopathic scoliosis reported that their mortality was similar to that of the normal population. Furthermore he reported 16 patients with a thoracic scoliotic angle greater than $80^{\circ}$ and yet found no one with respiratory failure. Our study confirms that respiratory failure develops in some patients with idiopathic scoliosis.

Predicting the development of respiratory failure in the future for a patient with unfused scoliosis is important so that respiratory failure can be recognised at an early stage, when treatment with assisted ventilation at night improves respiratory function ${ }^{20}$ and quality of sleep and may prolong life. ${ }^{21}$ This study confirms that a scoliotic angle greater than $110^{\circ}$, dyspnoea, and wheeze are markers of poor prognosis that call for follow up. Our main finding is that patients with idiopathic scoliosis who have reached skeletal maturity and have a VC below $45 \%$ predicted run an increased risk of developing respiratory failure when the aging process further reduces their lung function. Such patients should be followed carefully to recognise respiratory failure at an early stage.

The study was supported by the Swedish Heart-Lung Foundation and the Göteborg Medical Society. We thank laboratory
FEV (1)

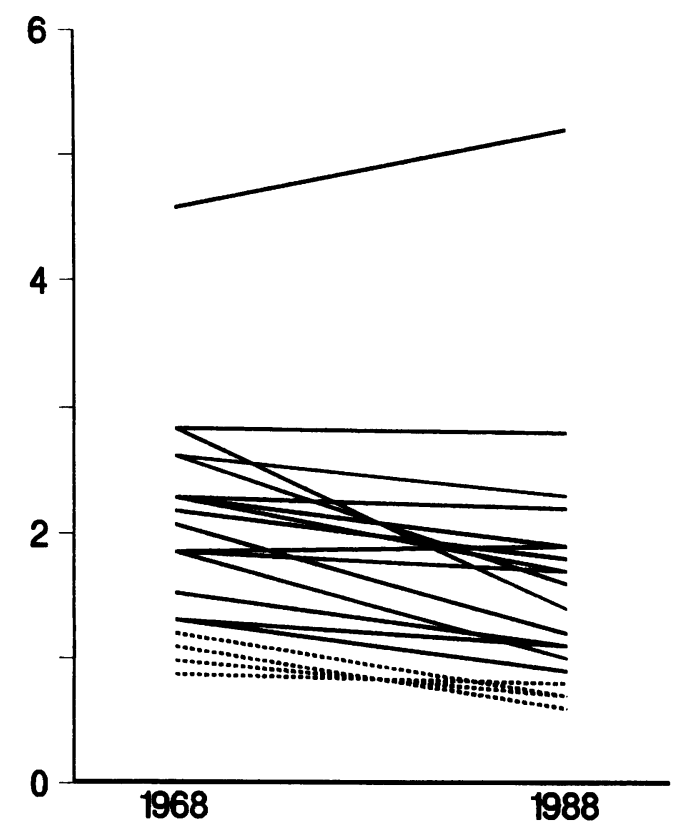

technician Eivor Jonasson for her skilful technical assistance and Nils-Gunnar Pehrsson for expert statistical guidance.

1 Bergofsky EH. Respiratory failure in disorders of the thoracic cage. Am Rev Respir Dis 1979;119:643-69.

2 Branthwaite MA. Cardiorespiratory consequences of unfused idiopathic scoliosis. Br J Dis Chest 1986;80: $360-9$.

3 Nachemson A. A long term follow-up study of non-treated scoliosis. Acta Orthop Scand 1968;39:466-76.

4 Nilsonne U, Lundgren K-D. Long-term prognosis in idiopathic scoliosis. Acta Orthop Scand 1968;39:456-65.

5 Lindh M, Bjure J. Lung volumes in scoliosis before and after correction by the Harrington instrumentation method. Acta Orthop Scand 1975;46:934-48.

6 Bjure J, Grimby G, Kasalichy J, Lindh M, Nachemson A. Respiratory impairment and airways closure in patients with untreated idiopathic scoliosis. Thorax 1970;25: 451-6.

7 Bake B, Bjure J, Kasalichy J, Nachemson A. Regional pulmonary ventilation and perfuson distribution in patients with untreated idiopathic scoliosis. Thorax 1972;27:703-12.

8 Cobb JR. Outline for the study of scoliosis. Am Acad Orthop Surg Lect 1948;5:261-75.

9 Chronic bronchitis in Great Britain. A national survey carried out by the respiratory diseases study group of the college of general practitioners. Br Med J 1961;ii:973-9.

10 Berglund E, Birath G, Bjure J, et al. Spirometric studies in normal subjects. Acta Med Scand 1963;173:185-206.

11 Decramer M, Demedts M, Rochette F, Billiet L. Maximal transrespiratory pressures in obstructive lung disease. Bull Eur Physiopathol Respir 1980;16:479-90.

12 Lurie M, Caidahl K, Johansson G, Bake B. Respiratory function in chronic primary fibromyalgia. Scand J Rehab Med 1990;22:151-5.

13 Bradley JV. Distribution-free statistical test. London: Prentice-Hall, 1968:78-80.

14 Press SJ, Wilson S. Choosing between logistic regression and discriminant analysis. Journal of the American Statistical Association 1978;73:699-705.

15 Kafer ER. Idiopathic scoliosis. Mechanical properties of the respiratory system and the ventilatory response to carbon respiratory system and the ventilatory $\mathrm{r}$
dioxide. $J$ Clin Invest 1975;55:1153-63.

16 Jones RS, Kennedy JD, Hasham F, Owen R, Taylor JF. Mechanical inefficiency in the thoracic cage in scoliosis. Thorax 1981;36:456-61.

17 Lisboa C, Moreno R, Fava M, Ferretti R, Cruz E. Inspiratory muscle function in patients with severe kyphoscoliosis. Am Rev Respir Dis 1985;132:48-52.

18 Weinstein SL, Ponseti I. Curve progression in idiopathic scoliosis. Long-term follow-up. J Bone Joint Surg 1983;65A:447-55.

19 Weinstein SL, Zavala DC, Ponseti IV. Idiopathic scoliosis. Long term follow-up and prognosis in untreated patients. J Bone Joint Surg 1981;63A:702-12.

20 Ellis ER, Grunstein RR, Shu Chan, Bye PTP, Sullivan CE. Noninvasive ventilatory support during sleep improves respiratory failure in kyphoscoliosis. Chest 1988;94:811-5.

21 Gerard M, Robert D, Salamand J, Buffat J, Chemorin B Bertoye A. Etude de la survie chez 150 insuffisants respiratoires chroniques tracheotomises traités par la ventilation assistée a domicile. Lyon Medical 1981; 245:555-8. 